\title{
CERVANTES Y LA CUESTIÓN MORISCA
}

\author{
ADRIANA LASSEL
}

Quisiera presentar en este estudio la relación de Cervantes con los moriscos y la plasmación literaria de sus vivencias. Esto lo encontramos, sobre todo, en su juventud, durante el cautiverio y en los años finales de su existencia, que corresponde a la expulsión de los hispanomusulmanes.

Por cierto, el joven Miguel de Cervantes compartió con los moriscos la misma tierra y conoció el problema político que oponía esta comunidad a la corona. Sabía también, como todo español de la época, el peligro que representaban los moriscos como cómplices y guías de los corsarios en sus ataques a las costas levantinas. Pero es en Argel donde estará enfrentado por primera vez, en cuanto cautivo cristiano, a la enemistad que sentía el morisco hacia los españoles.

La situación conflictiva que vivían los hispanomusulmanes desde la caída de Granada va a producir una migración constante de esta comunidad hacia África del Norte. La situación va a agudizarse después de la guerra de Alpujarras. Tanto el ambiente de guerra larvada con los ataques piratas a los pueblos costeros como la terrible realidad de la guerra de 1568 va a producir en el pueblo español un sentimiento común de odio hacia el morisco, sentimiento retribuido por estos. Conocida es la frase de Haedo o Sosa, refiriéndose a los moriscos: "Todos, en general, son los más grandes y crueles enemigos que los cristianos tienen en Berbería pues nunca apagan la sed de sangre cristiana que roe sus entra-

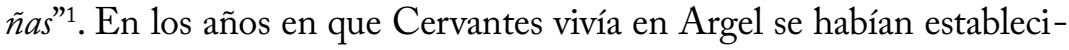
do en esta ciudad varias decenas de miles de moriscos y Antonio de Sosa, verdadero autor de la obra atribuida a Diego de Haedo, dice que Cherchell (Sargel) era un pueblo de tagarinos, con más de mil casas ${ }^{2}$.

${ }^{1}$ Citamos por la edición que tenemos a mano, publicada en Argel: Diego de Haedo, Topographie et Histoire Générale d'Alger, Argel, Editions Grand Alger Livres, 2004, p. 54. 
En el año de 1577 va a producirse en Argel un hecho del que Cervantes será testigo y al que va a reaccionar con una gran repulsa, en tanto español y cristiano y que llevará luego a su primera obra de teatro, esbozada posiblemente en el año mismo de su rescate (1580). El hecho es el siguiente: había en la ciudad de Cherchell una familia de moriscos provenientes del Reino de Valencia. Ali Cax, el hijo mayor, hombre de mar y conocedor de las costas españolas compró, junto a otros paisanos suyos, un bergantín de doce bancos y se dedicaron a la actividad del corso. En una ocasión, entre las personas que habían cautivado se encontraba un religioso llamado fray Miguel de Aranda. Sucedió que Ali Cax fue a su vez capturado y posteriormente, en abril de 1577, fue quemado públicamente en la ciudad de Valencia. El hermano de Ali Cax y los moriscos de Cherchell al conocer la noticia decidieron que si Ali había muerto en las llamas, en las llamas debía morir un cristiano en Argel. Decidieron que este cristiano debía ser fray Miguel de Aranda.

Una delegación morisca solicitó a Ramdane Pachá la autorización para la ejecución, y una vez que ésta fue acordada, dieron cruel muerte al religioso en la marina de la ciudad.

Este episodio, que he resumido brevemente, está contado por Antonio de Sosa en el relato 23 del libro «Diálogo de los mártires de Argel» que forma parte de la Topografía e Historia General de Argel. Cervantes reflejará esta historia en Los tratos de Argel, a través del diálogo entre un muchacho cautivo y un soldado cautivo, Saavedra. Dice Sebastián:
Ya sabes que aquí en Argel
se supo como en Valencia murió por justa sentencia un morisco de Sargel;
digo que en Sargel vivía, puesto que era de Aragón

${ }^{2}$ Ibid. "Les tagarins - explique cet ouvrage - sont les maures provenant de royaumes d'Aragon, de Valence et de la Catalogne". Véase también Antonio de Sosa, Diálogo de los mártires de Argel, Madrid, Hiperión, 1990, pp. 162-173. 
La triste nueva sabida

de los parientes del muerto,

juran y hacen concierto

de dar al fuego otra vida.

Buscaron luego un cristiano

para pagar este escote,

y halláronlo sacerdote,

y de nación valenciano ${ }^{3}$.

El cautivo Sebastián describe, en primera persona, los sufrimientos infligidos al religioso y el gozo de los moros en darle muerte:

[...] dicen, y yo he visto,

que, si alguna vez hablaba,

en el aire resonaba

el eco o nombre de cristo.

Y termina Sebastián:

Yo he venido a referiros

lo que no pudiste ver ${ }^{4}$.

Quisiera destacar tres puntos:

$1^{\circ}$ Miguel de Cervantes y Antonio de Sosa estarían en Argel en el momento de los hechos. Sabemos que, según las investigaciones de Georges Camamis ${ }^{5}$, la Topografía e Historia General de Argel fue escrita por Antonio de Sosa, tesis aceptada y seguida por Emilio Sola y José $\mathrm{M}^{\mathrm{a}}$ Parreño. Es posible que Cervantes no lo haya visto con sus propios ojos ("Yo he venido a referiros/ lo que no pudiste ver"), pero que haya sido un cercano testigo del triste ambiente que este hecho produjo, tanto en los cristianos como en la ciudad. En cuanto a de Sosa, siempre encerrado en el calabozo donde lo tenía su amo el judío Mohamed, estamos seguros de que no fue testigo presencial. Esto descarta cualquier relación de influencia entre Cervantes y la Topografía. María Concepción Ortiz Bordillo, en su tesis doctoral de 1987, nos da todavía esta relación entre Cervantes y Haedo: "La obra de Haedo confirma el relato dramático de Cervantes, ya que recoge la

${ }^{3}$ Miguel de Cervantes Saavedra, Obras Completas, edición de Ángel Valbuena Prat, Madrid, Aguilar, 1970, tomo 1, p.136.

${ }^{4}$ Ibid., pp. 136-138.

${ }^{5}$ Antonio de Sosa, ob. cit., 1990, p. 11 
historia de este morisco y aunque no es la fuente [...] nos sirve como documento para destacar la relevancia del suceso, reflejado en ambos cautivos"6.

$2^{\circ}$ Hay en las versiones de Cervantes y de Sosa una diferencia que muestra que, aunque estando en el mismo lugar, los dos autores describen el hecho separadamente. En efecto, en el relato de de Sosa, la familia morisca es de la región de Valencia, como fray Miguel de Aranda. En Cervantes, la familia morisca es de Aragón.

$3^{\circ}$ En este primer acercamiento de Cervantes al tema morisco, su sentimiento es de total condena hacia la crueldad y venganza de éstos, actitud que pudo conocer directamente en su cautiverio en Argel.

\section{II}

Algunos estudiosos, como Canavaggio ${ }^{7}$, sitúan la aparición de Los tratos de Argel entre 1581 y 1587, vale decir, pocos años después del regreso del cautiverio, cuando la amarga experiencia estaba todavía cercana. Las dos obras a que me referiré ahora, El coloquio de los perros (1613) y la segunda parte del Quijote (1615), muestran que por esas fechas el autor ya sabe que la guerra de la corona española contra los turcos y corsarios argelinos se limitará a una guerra interna contra los moriscos, una marginalización y desprestigio de esta comunidad.

No sabemos si Cervantes tuvo un amigo morisco, en España. Es posible que haya tratado con algunos. Sus obras muestran caracteres individuales y generalizaciones. Cuando se refiere a un morisco en particular su caracterización es variada y rica, como en los casos de Ricote, de su hija Ana Félix, del moro del Alcaná de Toledo, o del traductor de Cidi Hamete Benengali. En cuanto a éste, según Luce Lopez-Baralt, en su estudio sobre la identidad islámica de Benengali, éste tiene más de moro que de morisco. Estoy completamente de acuerdo con ella cuando afirma "Cide tenía, no cabe duda, un grave problema de identidad" 8 .

${ }^{6}$ María Concepción Ortiz Bordallo, Argel en el teatro español del siglo de oro, Madrid, Universidad Complutense, tesis doctoral, 1987, p. 204.

${ }^{7}$ Jean Canavaggio, “Cervantès dramaturge (un théâtre à naître)", París, PUF, 1977, citado en Romo Feito, "La victoria en la derrota y la diferencia religiosa en Cervantes", Cervantes y las religiones, Madrid, Iberoamericana/Vervuert, 2008, p. 709.

${ }^{8}$ Luce López-Baralt, "El sabio encantador Cide Hamete Benengali: ¿̨fue un musulmán de al-Andalus o un morisco del siglo XVII?”, en ibidem., p. 339. 
Cuando Cervantes habla de los moriscos en forma general se hace el portavoz del lenguaje oficial y de la opinión común del cristiano viejo. Esto ha originado muchas interpretaciones, algunas de las cuales consideran a Cervantes un antimorisco. En El coloquio de los perros, el perro Berganza dice del morisco: "Todo su intento es acuñar y guardar dinero [...] ganando siempre y gastando nunca amontonan la mayor cantidad de dinero que hay en España" 9 . El perro les reprocha, además que no crean en la sagrada ley cristiana, que no vayan a la guerra, que no se hagan religiosos y "róbannos [...] y con los frutos de nuestras heredades, que nos revenden, se hacen ricos".

No olvidemos lo profundamente arraigado que estaba en la ideología de la época el valor de la "limpieza de sangre", es decir, no poseer ni sangre mora ni judía. En consecuencia, el morisco, por muy buen cristiano que mostrara ser, nunca sería un limpio de sangre. De allí que los reproches de que no crean en la ley cristiana y de que no entren en las órdenes religiosas, dentro del contexto de la época, eran defectos de importancia para un cristiano viejo, pero no para un espíritu liberal y conocedor de las nuevas ideas de la Contrarreforma, como Cervantes.

$\mathrm{El}$ acercamiento que estoy haciendo entre la experiencia vivida por Cervantes en su juventud y la relación con su tratamiento literario de la cuestión morisca me permite pensar que el hecho de haber conocido en Argel la interculturalidad y el mestizaje ideológico de tantos cristianos convertidos al Islam (dejemos de lado la razón de por qué lo hicieron) dio al escritor una comprensión excepcional hacia la identidad morisca. Cervantes conoció en Argel el caso de los renegados o convertidos al Islam, personas que mantenían en el fondo de ellos su cultura y lengua nativas. Si no aceptó el reniego para él mismo, tuvo comprensión hacia los que vivían una doble identidad. ¿Por qué, entonces, en España, años más tarde, iba a tener una actitud de condena hacia los que vivían y sufrían esta dualidad? Me resulta difícil aceptar que apruebe el lenguaje oficial que él pone en boca de Berganza.

\footnotetext{
${ }^{9}$ Miguel de Cervantes Saavedra, ob. cit., 1970, Tomo II, p. 1199.
} 


\section{III}

La tercera obra que he escogido para tratar este tema es la segunda parte del Quijote, capítulo 54, donde aparecen el morisco Ricote y Sancho, sin olvidar que el morisco había sido el tendero del pueblo de Sancho. Estos dos personajes, pues, van a encontrarse en un camino rural. Sancho acababa de abandonar la Ínsula y su gobierno y partía a buscar a su amo, don Quijote. Ricote regresaba clandestinamente a España disfrazado de romero, junto a otros cinco peregrinos extranjeros.

No me voy a alargar en la caracterización de este personaje, bastante estudiado. Sólo recordaré que frente a él hay dos puntos de vista: uno, en el cual Cervantes habría, por medio de Ricote, apoyado los decretos de expulsión. Ricote, en el capítulo LXIII, afirma que los moriscos "justamente han sido desterrados" y alaba al Conde de Salazar "a quien dio Su Majestad cargo de nuestra expulsión”. El otro punto de vista ve en Cervantes una actitud comprensiva hacia este morisco, puesto que conoce en carne propia el dolor de estar obligado a vivir lejos de su patria y conoce, también, la falta de libertad religiosa que existía en España.

Después de que ambos se saludaran, con alegría por parte de $\mathrm{Ri}$ cote y asombro por parte de Sancho, el morisco cuenta que buscando un lugar donde vivir encontró que en Alemania "se podía vivir con más libertad, porque sus habitadores no miran en muchas delicadezas; cada uno vive como quiere, porque en la mayor parte de ella se vive con libertad de conciencia ${ }^{10}$. Parece que esta frase "libertad de conciencia” tiene una significación diferente de lo que podemos leer a primera vista. Helena Percas de Ponseti en su libro Cervantes y su concepto del arte cita a Joaquín Casalduero y a Alejandro RamirezAraujo, para quienes esta frase tendría un sentido peyorativo, un sentido de 'desenfreno'. Dicho así, Cervantes al hacer vivir a Ricote en Alemania, no estaría alabando la libertad de culto de este país ${ }^{11}$.

Creo que Cervantes quiere decir lo que todos entendemos por libertad de conciencia y que viene definida en el diccionario de la Real

${ }^{10}$ Ibid., p. 1700.

${ }^{11}$ Helena Percas de Ponseti, Cervantes y su concepto del arte, Madrid, Editorial Gredos, 1975, pp. 268-269, nota 35 . 
Academia Española como "la facultad de profesar cualquier religión sin ser inquietado por la autoridad pública”.

Volvamos, otra vez, a la experiencia de Argel, donde Cervantes se enfrentó a la persecución por supuestas razones morales hechas por un religioso que fingía ser Comisario de la Inquisición, Juan Blanco de Paz. La Inquisición, como instrumento de la autoridad, era el reflejo de la falta de conciencia que encontrará más tarde, al regresar a España. La palabra 'conciencia', con su sentido actual aparecerá tres veces en la declaración de Domingo Lopino, uno de los testigos de la Información de 1580, ante notario. Pienso que la palabra 'conciencia' que Cervantes usa en este capítulo del Quijote, a comienzos del siglo XVII, tiene el mismo sentido con que la usó Lopino al decir que Cervantes "era temeroso de Dios y de su conciencia", y al calificar a Blanco de Paz como un hombre "de mala conciencia".

En conclusión, el acercamiento de Cervantes a la cuestión morisca no es monolítico: comienza con un enfoque negativo, como resultado de su reciente cautiverio; es ambiguo al darnos la versión oficial y el sentimiento antimorisco del cristiano viejo; pero en los años de la expulsión eleva el asunto morisco a la categoría de problema humanitario. Estoy de acuerdo con Joaquín Casalduero cuando dice que en 1615 Cervantes separa el tema de la realidad social histórica y lo eleva al plano novelesco de los sentimientos humanos. 